\title{
Venoarterial extracorporeal membrane oxygenation for postcardiotomy shock: Risk factors for mortality
}

Thomas Fux, MD, ${ }^{\mathrm{a}, \mathrm{b}}$ Manne Holm, MD, ${ }^{\mathrm{c}}$ Matthias Corbascio, MD, PhD, ${ }^{\mathrm{c}, \mathrm{d}}$ Lars H. Lund, MD, PhD, ${ }^{\mathrm{a}, \mathrm{d}}$ and Jan van der Linden, $\mathrm{MD}, \mathrm{PhD}^{\mathrm{b}, \mathrm{c}}$

\section{ABSTRACT}

Objectives: Refractory postcardiotomy cardiogenic shock is associated with a high mortality, and venoarterial extracorporeal membrane oxygenation can offer acute cardiopulmonary life support. The aim of this study was to identify pre-venoarterial extracorporeal membrane oxygenation risk factors of 90-day mortality.

Methods: We retrospectively analyzed 105 consecutive patients supported with venoarterial extracorporeal membrane oxygenation due to refractory postcardiotomy cardiogenic shock. The association between preimplant variables and all-cause mortality at 90 days was analyzed with univariable and multivariable logistic regression.

Results: Main surgical subgroups were single noncoronary artery bypass grafting (29\%), isolated coronary artery bypass grafting (20\%), and 2 and 3 concomitant surgical procedures $(31 \%$ and $20 \%$, respectively). The median age of patients was 62 years (interquartile range, 52-68 years), and 76\% were men. Cardiopulmonary resuscitation was performed in $30 \%$ of patients before venoarterial extracorporeal membrane oxygenation initiation. The median duration of venoarterial extracorporeal membrane oxygenation was 7 days (interquartile range, 3-14). The 90-day overall mortality was 57\%, and in-hospital mortality was $56 \%$. Forty-seven percent of patients died on venoarterial extracorporeal membrane oxygenation, $51 \%$ of patients were successfully weaned, $1 \%$ of patients were bridged to heart transplantation, and $1 \%$ of patients were bridged to left ventricular assist device. Multivariable logistic regression analysis identified arterial lactate (odds ratio per unit, 1.22; 95\% confidence interval, 1.07-14.0; $P=.004$ ) and ischemic heart disease (odds ratio, $7.87 ; 95 \%$ confidence interval, $2.55-24.3 ; P<.001)$ as independent risk factors of 90-day mortality.

Conclusions: In patients with postcardiotomy cardiogenic shock, ischemic heart disease and level of arterial lactate before venoarterial extracorporeal membrane oxygenation initiation were identified as independent pre-venoarterial extracorporeal membrane oxygenation risk factors of 90-day mortality. These risk factors are easily available for pre-venoarterial extracorporeal membrane oxygenation risk prediction and may improve patient selection for this resourceintensive therapy. (J Thorac Cardiovasc Surg 2018;156:1894-902)

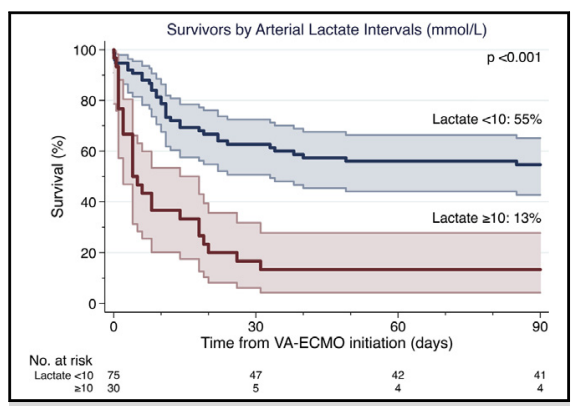

The 90-day survival in patients with PCS related to lactate intervals at initiation of VA-ECMO.

\section{Central Message}

In patients with refractory PCS, lactate and IHD were independent predictors of 90-day mortality after initiation of VA-ECMO, whereas age, type of surgery, EuroSCORE II, CBP duration, or AMI were not.

\section{Perspective}

VA-ECMO offers reasonable 90-day survival in selected patients with refractory PCS and should be initiated before profound hyperlactatemia occurs, especially in patients with IHD. The correlation between duration of VAECMO and in-hospital mortality indicates that weaning should be individualized and delayed until cardiopulmonary parameters are fully optimized.

See Editorial Commentary page 1903.

See Editorial page 1883 .
From the Departments of ${ }^{a}$ Medicine and ${ }^{c}$ Molecular Medicine and Surgery, Karolinska Institutet, Stockholm, Sweden; ${ }^{\mathrm{b}}$ Division of Perioperative Medicine and Intensive Care, Section Cardiothoracic Surgery and Anesthesiology, and ${ }^{\mathrm{d}}$ Heart and Vascular Division, Karolinska University Hospital, Stockholm, Sweden.

Date and Number of Institutional Review Board Approval: The Regional Ethics Review Board in Stockholm approved this study (Project No. 2008/1695-31 and 2012/ 119-32).
Received for publication Oct 4, 2017; revisions received May 10, 2018; accepted for publication May 14, 2018; available ahead of print June 29, 2018.

Address for reprints: Thomas Fux, MD, Division of Perioperative Medicine and Intensive Care Section Cardiothoracic Surgery and Anesthesiology, Karolinska University Hospital, SE-171 76 Stockholm, Sweden (E-mail: thomas.fux@sll.se). $0022-5223 / \$ 36.00$

Copyright (c) 2018 by The American Association for Thoracic Surgery https://doi.org/10.1016/j.jtcvs.2018.05.061 


\section{Abbreviations and Acronyms \\ AIC $=$ Akaike information criterion \\ AMI = acute myocardial infarction \\ BIC = Bayesian information criterion \\ $\mathrm{CABG}=$ coronary artery bypass grafting \\ $\mathrm{CPB}=$ cardiopulmonary bypass \\ euroSCORE $=$ European System for Cardiac \\ Operative Risk Evaluation \\ IHD $=$ ischemic heart disease \\ IQR $\quad=$ interquartile range \\ OR $=$ odds ratio \\ PCS $=$ postcardiotomy cardiogenic shock \\ RPCS $=$ refractory postcardiotomy \\ cardiogenic shock \\ $\mathrm{VAD}=$ ventricular assist device \\ VA-ECMO = venoarterial extracorporeal membrane oxygenation}

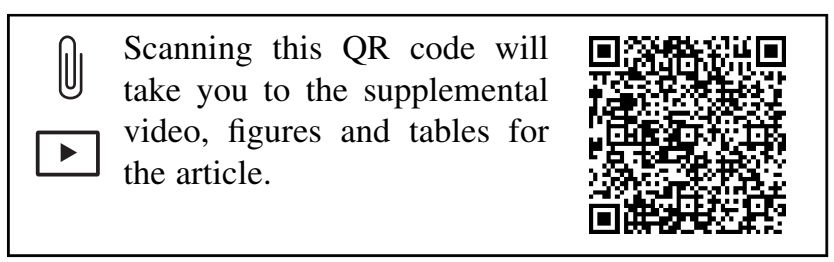

Postcardiotomy cardiogenic shock (PCS), defined as low cardiac output syndrome with evidence of tissue hypoperfusion and end-organ dysfunction despite adequate preload, affects $0.2 \%$ to $6 \%$ of patients who undergo cardiothoracic surgery. ${ }^{1-3}$ PCS is a life-threatening complication with mortality rates between $50 \%$ and $80 \%{ }^{4-6}$ and includes the inability to wean from cardiopulmonary bypass (CPB) in the operating room or deterioration of myocardial function during the first postoperative days. Between $70 \%$ and $90 \%$ of the patients who cannot be easily separated from CPB because of PCS can be weaned from CPB by support of inotropes, vasopressors, and intraaortic balloon pumps, and an estimated two thirds of these patients will recover hemodynamically without the need for other mechanical circulatory support. ${ }^{7,8}$ In comparison, PCS refractory to intravascular volume loading, pharmacologic, and intra-aortic balloon pump support occurs postoperatively in $0.5 \%$ to $1.5 \%{ }^{7}$ of patients and will inexorably lead to death unless more efficient circulatory support is initiated.

Venoarterial extracorporeal membrane oxygenation (VAECMO) can temporarily provide partial or complete cardiopulmonary support in patients with refractory PCS (RPCS) as a bridge to myocardial recovery, heart transplantation, long-term ventricular assist device (VAD), or other interventions. $^{9-11}$ VA-ECMO is initiated in $0.6 \%$ to $2.9 \%$ of patients after routine cardiothoracic surgery. ${ }^{11-18}$ Despite VA-ECMO support, the in-hospital mortality rate is $53 \%$ to $84 \%{ }^{6,18-22}$ and is influenced by patient characteristics and surgical case mix. ${ }^{11,13,16}$ Previous studies have focused on a combination of preoperative, surgical, and on-VA-ECMO (ie, during support) variables to identify risk factors for mortality. ${ }^{12-14,16-18,23,24}$ However, it is problematic to include on-VA-ECMO factors if the specific aim is to identify preimplant risk factors to facilitate early risk prediction to better use and prioritize this technique for appropriate patients with RPCS. Thus, the aim was to identify independent preVA-ECMO risk factors for 90-day mortality in an unselected population with RPCS supported by VA-ECMO.

\section{MATERIALS AND METHODS \\ Study Population}

We retrospectively reviewed the medical records of 105 consecutive patients who received VA-ECMO support for RPCS between September 2006 and April 2015 at our institution. The Regional Ethics Review Board approved this study (Project No. 2008/1695-31 and 2012/119-32). There are no universal criteria or specific indications for initiation of VA-ECMO support in RPCS. Our unit considers VA-ECMO as a salvage therapy due to inability to wean from $\mathrm{CPB}$ or the development of poor hemodynamics and evidence of persistent tissue hypoperfusion in the early postoperative period, despite adequate intravascular volume loading and pharmacologic support, when there is potential for recovery, heart transplantation, or left VAD implantation. No short-term VADs were used for RPCS during the period of this study because the likelihood of death was considered extremely high without VA-ECMO providing sufficient biventricular support. The VA-ECMO circuit, implantation technique, and patient management during VA-ECMO are not the scope of this study and have been described. . $^{9,10,24}$

\section{Data Collection}

The patients were included in the study irrespective of locality or timing of VA-ECMO initiation, that is, intraoperatively or postoperatively in the intensive care unit. Patients' characteristics, surgical procedure, and clinical and laboratory data at VA-ECMO initiation (ie, just before cannulation) were together with complications and outcome data obtained from the medical records. Patients were subdivided into 4 mutually exclusive cardiac surgical subgroups according to the European System for Cardiac Operative Risk Evaluation (euroSCORE) II classification: single noncoronary artery bypass grafting (non-CABG), isolated CABG, and 2 and 3 concomitant surgical procedures. Type of cannulation and complications were presented for descriptive purposes but not included in the statistical analysis because they were not pre-VA-ECMO factors.

\section{Baseline Definitions}

Ischemic heart disease (IHD) was defined as a history of myocardial infarction, angina pectoris, percutaneous coronary intervention/CABG, or when prior coronary angiography had shown evidence of coronary artery disease according to multidisciplinary conferences, chronic renal failure as the estimated preoperative glomerular filtration rate of less than $60 \mathrm{~mL} / \mathrm{min} / 1.73 \mathrm{~m}^{2}$ present for more than 3 months (in accordance with the US National Kidney Foundation Kidney Disease Outcomes Quality Initiative guidelines 2012), number of inotropes and vasopressors as the total number of intravenous inotropes and vasopressors (epinephrine, norepinephrine, dobutamine, dopamine, vasopressin, milrinone, levosimendan), pre-VA-ECMO data as the latest clinical 
and laboratory data just before VA-ECMO cannulation, and data defined "prior" refers to data previous to the current medical event/admission. Cardiopulmonary resuscitation included all cardiopulmonary resuscitation episodes from the time of the current hospital admission: preoperative (before $\mathrm{CPB}$ ) and postoperative until initiation of VA-ECMO.

\section{Statistical Analysis}

The descriptive analysis compared pre-VA-ECMO variables between survivors and nonsurvivors at 90 days after VA-ECMO initiation. Categoric variables were presented as numbers and percentages, and compared with the chi-square, likelihood ratio, or Fisher exact tests. Non-normally distributed continuous variables were expressed as median and interquartile range (IQR), and compared with the Mann-Whitney $U$ test. Logistic regression was used to assess the impact of pre-VA-ECMO variables on likelihood for death at 90 days after VA-ECMO initiation. Variables identified as being significant in the univariable analysis were subjected to multicollinearity analysis by using the Spearman rho correlation coefficient before multivariable logistic regression analysis. Five variables, none with missing data, were included in the multivariable logistic regression model to determine the independent associations between pre-VA-ECMO implant variables and 90-day mortality. To assess the impact of nonlinearity on the logistic regression analysis, the continuous variables included in the model were transformed by using restricted cubic splines with both 3 and 4 knots (default placements). Logistic regression was subsequently performed with the categoric variables included in the 2 spline models with 3 and 4 knots, respectively. The acquired Akaike information criterion (AIC) and Bayesian information criterion (BIC) values were then compared with the corresponding AIC and BIC values of the original model. Goodness of fit was verified by the Hosmer-Lemeshow test. Cumulative survival curves for 90-day follow-up were generated using the Kaplan-Meier method, and arbitrary chosen subgroups were compared using the log-rank test. All statistical analyses were performed with SPSS version 23 for Windows (IBM SPSS Statistics, New York, NY).

\section{RESULTS}

No patients were lost to follow-up, and there were no VAECMO device-related deaths. Pre-VA-ECMO variables and comparison between survivors and nonsurvivors at 90 days after VA-ECMO initiation are summarized in Table 1. Median age was 62 years (IQR, 52-68), which was significantly lower in survivors (60 years; IQR, 4966) compared with nonsurvivors (65 years; IQR, 54-69; $P=.017)$. Of the surgical subgroups, only isolated CABG differed significantly between survivors and nonsurvivors, with a 90-day mortality of $86 \%$. Acute myocardial infarction (AMI) and IHD were present in $27 \%$ and $57 \%$ of the patients with an $82 \%$ and $77 \%$ 90-day mortality, respectively. Median left ventricular ejection fraction, mean arterial pressure, and arterial $\mathrm{pH}$ just before cannulation were significantly lower among nonsurvivors compared with survivors, whereas the inverse relationship was significant for age, euroSCORE II, prior CABG, arterial lactate, alanine aminotransferase, and total number of inotropes and vasopressors (epinephrine, norepinephrine, dobutamine, dopamine, vasopressin, milrinone, levosimendan).

Eight variables were found significantly associated with 90-day mortality by univariable logistic regression: age, isolated CABG, AMI, IHD, left ventricular ejection fraction, mean arterial pressure, arterial $\mathrm{pH}$, and lactate (Table E1). There were strong correlations between arterial $\mathrm{pH}$ and lactate (rho $=-0.713 ; P<.001$ ), AMI and IHD $($ rho $=0.522 ; P<.001)$, CABG and IHD $($ rho $=0.433$; $P<.001$ ), and CABG and AMI (rho $=0.829 ; P<.001$ ), respectively. Arterial $\mathrm{pH}, \mathrm{AMI}$, and $\mathrm{CABG}$, the latter 2 being included in the variable IHD, were all 3 excluded from the model, leaving 5 variables in the model (Table 2). We favored exclusion of $\mathrm{pH}$ and not lactate, because the latter is a more robust variable less sensitive to the influence of $\mathrm{PaCO}_{2}$ and administration of buffer solutions in the acute setting.

When assessing AIC, our original model had a value of 102, compared with 105 (3 knots) and 104 (4 knots). The corresponding BIC values were 118, 131 ( 3 knots), and 141 (4 knots), respectively. Because of similar values in both AIC and BIC, the approach of nonlinearity through splines did not seem to affect the logistic regression analysis in a problematic way, which supports the use of the model without transformations and facilitates clinical interpretation. The model was statistically significant, chi-square $(5, \mathrm{n}=105)=52.911 ; P<.001$, indicating that the model was able to distinguish between survivors and nonsurvivors at 90 days. Chi-square for Hosmer-Lemeshow test was 2.952 with a significance level of $P$ of .937 , thereby further supporting that the overall fit of the model was good. The model as a whole explained between $39.6 \%$ (Cox and Snell $\mathrm{R}^{2}$ ) and $53.1 \%$ (Nagelkerke $\mathrm{R}^{2}$ ) of the variance of 90-day mortality and overall correctly classified $80.0 \%$ of the cases. The sensitivity of the model was $85 \%$ (true positives) and specificity was $73.3 \%$ (true negatives), giving positive and negative predictive values of $81 \%$ and $79 \%$, respectively.

In multivariable logistic regression, only 2 of the independent variables made a unique statistical significant contribution to the model (Table 2). The most significant risk factor being presence of IHD (odds ratio [OR], 7.87; 95\% confidence interval, 2.55-24.3; $P<.001$ ), followed by arterial lactate (OR per mmol/L increase: $1.22 ; 95 \%$ confidence interval, 1.07-1.40, $P=.004)$. Outcome data including events after initiation of VA-ECMO and causes of death within 90 days are presented in Table 3. The median duration of VA-ECMO was 7 days (IQR, 3-14). Death during VA-ECMO occurred in $47 \%(\mathrm{n}=49)$ of the patients, $51 \%(\mathrm{n}=54)$ were successfully weaned, $2 \%(\mathrm{n}=2)$ did not tolerate weaning, $1 \%(\mathrm{n}=1)$ were bridged to heart transplantation, and $1 \%(\mathrm{n}=1)$ were bridged to left VAD. The in-hospital mortality was $56 \%(\mathrm{n}=59)$, and $44 \%(n=46)$ were discharged home. The median number of days from initiation of VA-ECMO to discharge home was 64 (IQR, 41-105; range 13-212). The primary end point overall 90-day mortality after initiation of VA-ECMO was $57 \%(n=60)$. The overall mortality at 24,48 , and 72 hours, 
TABLE 1. Comparison of pre-venoarterial extracorporeal membrane oxygenation characteristics between survivors and nonsurvivors at 90 days after venoarterial extracorporeal membrane oxygenation initiation

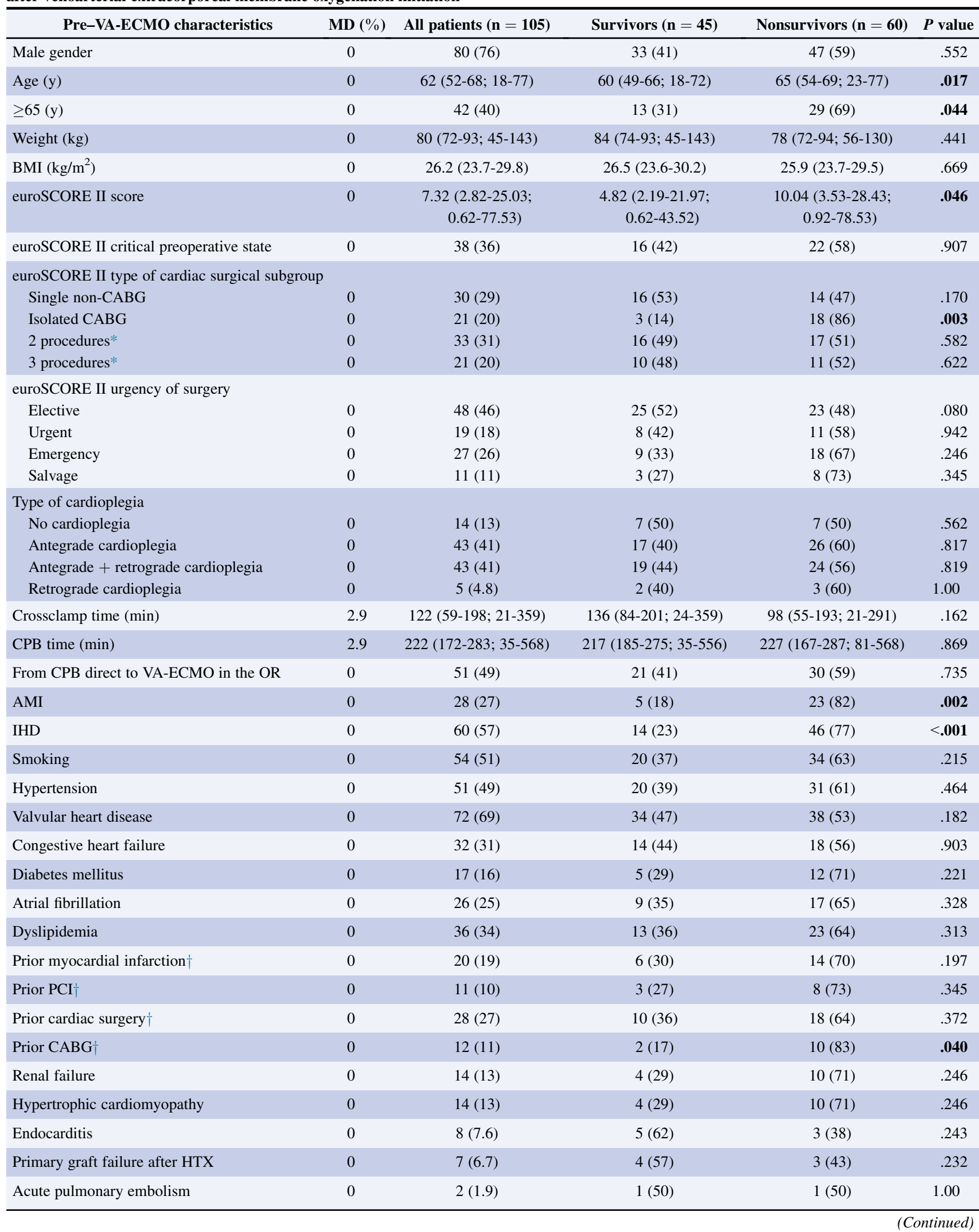


TABLE 1. Continued

\begin{tabular}{|c|c|c|c|c|c|}
\hline Pre-VA-ECMO characteristics & MD $(\%)$ & All patients $(n=105)$ & Survivors $(n=45)$ & Nonsurvivors $(\mathrm{n}=\mathbf{6 0})$ & $P$ value \\
\hline $\operatorname{LVEF}(\%)$ & 0 & $25(13-50)$ & $33(18-55)$ & $15(0-29)$ & $<.001$ \\
\hline$<20(\%)$ & 0 & $50(48)$ & $12(24)$ & $38(76)$ & $<.001$ \\
\hline $\mathrm{MAP}(\mathrm{mm} \mathrm{Hg}) \ddagger$ & 0 & $50(40-64)$ & $60(49-68)$ & $47(40-60)$ & .001 \\
\hline$<50(\mathrm{~mm} \mathrm{Hg})$ & 0 & $44(42)$ & $11(25)$ & $33(75)$ & .002 \\
\hline Arterial $\mathrm{pH} \ddagger$ & 0 & $7.26(7.13-7.32 ; 6.75-7.49)$ & $7.29(7.18-7.35 ; 6.84-7.46)$ & $7.22(7.09-7.31 ; 6.75-7.49)$ & .009 \\
\hline Arterial lactate $(\mathrm{mmol} / \mathrm{L}) \ddagger$ & 0 & $7.0(3.2-11.5 ; 0.7-28.0)$ & $4.0(2.0-8.6 ; 0.7-14.7)$ & $8.0(5.4-14.9 ; 0.7-28.0)$ & $<.001$ \\
\hline$<5(\mathrm{mmol} / \mathrm{L})$ & 0 & $39(37)$ & $25(64)$ & $14(36)$ & - \\
\hline $5-9.9(\mathrm{mmol} / \mathrm{L})$ & 0 & $36(34)$ & $16(44)$ & $20(56)$ & - \\
\hline $10-14.9(\mathrm{mmol} / \mathrm{L})$ & 0 & $16(15)$ & $4(25)$ & $12(75)$ & - \\
\hline$\geq 15(\mathrm{mmol} / \mathrm{L})$ & 0 & $14(13)$ & $0(0)$ & $14(100)$ & $<.001$ \\
\hline Hemoglobin $(\mathrm{g} / \mathrm{L}) \ddagger$ & & $93(86-106)$ & $94(85-109)$ & $93(86-104)$ & .964 \\
\hline WBC $\left(10^{9} / \mathrm{L}\right)$ & 0 & $10.8(7.2-15.7)$ & $10.4(7.2-16.7)$ & $11.2(7.2-14.8)$ & .568 \\
\hline Platelets $\left(10^{9} / \mathrm{L}\right)$ & 0 & $161(95-234)$ & $157(108-228)$ & $161(87-240)$ & .991 \\
\hline Creatinine $(\mu \mathrm{mol} / \mathrm{L})$ & 0 & $120(92-169)$ & $110(79-159)$ & $124(95-189)$ & .103 \\
\hline GFR MDRD $\left(\mathrm{mL} / \mathrm{min} / 1.73 \mathrm{~m}^{2}\right)$ & 0 & $55(37-73)$ & $62(41-89)$ & $53(33-70)$ & .074 \\
\hline ALT ( $\mu$ kat/L) & 5.7 & $0.82(0.40-2.11)$ & $0.69(0.34-1.32)$ & $1.06(0.54-2.80)$ & .041 \\
\hline \multicolumn{6}{|l|}{ Pre-VA-ECMO interventions } \\
\hline Acute PCI & 0 & $7(6.7)$ & $2(29)$ & $5(71)$ & .696 \\
\hline Hemodialysis & 0 & $24(23)$ & $10(42)$ & $14(58)$ & .893 \\
\hline CPR & 0 & $31(30)$ & $12(39)$ & $19(61)$ & .578 \\
\hline Intra-aortic balloon pump & 0 & $5(4.8)$ & $1(20)$ & $4(80)$ & .389 \\
\hline No. of inotropes and vasopressors $\S$ & 0 & $3(2-4)$ & $2(2-3)$ & $3(2-4)$ & .046 \\
\hline Retrieval from external hospital & 0 & $24(23)$ & $8(33)$ & $16(67)$ & .283 \\
\hline \multicolumn{6}{|l|}{ VA-ECMO insertion period } \\
\hline $2006-2010$ & 0 & $55(52)$ & $19(35)$ & $36(65)$ & - \\
\hline 2011-2015 & 0 & $50(48)$ & $26(52)$ & $24(48)$ & .071 \\
\hline
\end{tabular}

Bold indicates statistical significance. Categoric variables are presented as n (\%) and compared with the chi-square, likelihood ratio, or Fisher exact test. Continuous variables are presented as median (IQR; range) and compared with the Mann-Whitney $U$ test. VA-ECMO, Venoarterial extracorporeal membrane oxygenation; $M D$, missing data; $B M I$, body mass index; euroSCORE, European System for Cardiac Operative Risk Evaluation; $C A B G$, coronary artery bypass grafting; $C P B$, cardiopulmonary bypass; $O R$, operating room; $A M I$, acute myocardial infarction; $I H D$, ischemic heart disease; $P C I$, percutaneous coronary intervention; $H T X$, heart transplantation; $L V E F$, left ventricular ejection fraction; $M A P$, mean arterial pressure; $W B C$, white blood cell count; GFR MDRD, glomerular filtration rate modification of diet in renal disease; $A L T$, alanine aminotransferase; $C P R$, cardiopulmonary resuscitation. *Number of surgical interventions on the heart (euroSCORE II classification). $\dagger$ Before current medical event/admission. $\ddagger$ Just before cannulation. $\S$ Epinephrine, norepinephrine, dobutamine, dopamine, vasopressin, milrinone, and levosimendan.

and 7 and 30 days were $11 \%, 11 \%, 15 \%, 25 \%$, and $51 \%$, respectively. Multiple organ failure was the main cause of death both on VA-ECMO $(49 \%, 24$ of 49 deaths $)$ and within 90 days after its initiation (59\%, 29 of 49 deaths).

The main complications after VA-ECMO initiation are provided in Figure E1, with the most frequent being renal failure necessitating hemodialysis $(70 \%)$, reexploration $(68 \%)$, pneumonia $(61 \%)$, sepsis $(24 \%)$, and ischemic stroke $(16 \%)$. In patients with peripheral $(76 \%, \mathrm{n}=80)$ and central cannulation $(24 \%, \mathrm{n}=25)$, the 90 -day mortality was $51 \%$ and $76 \%$, respectively. Distal perfusion catheter was used in $90 \%(\mathrm{n}=72)$ of patients with peripheral

TABLE 2. Factors associated with mortality within 90 days after venoarterial extracorporeal membrane oxygenation initiation

\begin{tabular}{|c|c|c|c|c|c|}
\hline \multirow[b]{2}{*}{ Variables } & \multirow[b]{2}{*}{ MD (\%) } & \multicolumn{2}{|c|}{ Univariable logistic regression } & \multicolumn{2}{|c|}{ Multivariable logistic regression } \\
\hline & & OR $(95 \%$ CI $)$ & $P$ value & OR $(95 \%$ CI $)$ & $P$ value \\
\hline Age $(y)$ & 0 & $1.04(1.01-1.07)$ & .017 & $1.04(0.99-1.09)$ & .058 \\
\hline IHD & 0 & $7.28(3.05-17.4)$ & $<.001$ & $7.87(2.55-24.3)$ & $<.001$ \\
\hline $\operatorname{LVEF}(\%) *$ & 0 & $0.96(0.94-0.98)$ & $<.001$ & $0.98(0.95-1.01)$ & .112 \\
\hline MAP $(\mathrm{mm} \mathrm{Hg}) *$ & 0 & $0.96(0.94-0.99)$ & .007 & $0.98(0.95-1.04)$ & .243 \\
\hline Arterial lactate $(\mathrm{mmol} / \mathrm{L})^{*}$ & 0 & $1.21(1.10-1.33)$ & $<.001$ & $1.22(1.07-1.40)$ & .004 \\
\hline
\end{tabular}

Bold indicates statistical significance. $M D$, Missing data; $O R$, odds ratio; $C I$, confidence interval; $I H D$, ischemic heart disease; $L V E F$, left ventricular ejection fraction; $M A P$, mean arterial pressure. *Just before cannulation. 
TABLE 3. Outcomes

\begin{tabular}{|c|c|c|}
\hline Variables & MD $(\%)$ & $\begin{array}{l}\text { All patients } \\
(\mathbf{n}=\mathbf{1 0 5})\end{array}$ \\
\hline \multicolumn{3}{|l|}{ VA-ECMO duration } \\
\hline Days & 0 & $7(3-14 ; 1-55)$ \\
\hline Single non-CABG $(\mathrm{n}=30)$ & 0 & $8(4-25)$ \\
\hline Isolated CABG $(\mathrm{n}=21)$ & 0 & $6(2-11)$ \\
\hline 2 procedures* $(\mathrm{n}=33)$ & 0 & $9(5-17)$ \\
\hline 3 procedures* $(\mathrm{n}=21)$ & 0 & $5(3-11)$ \\
\hline \multicolumn{3}{|l|}{ VA-ECMO destination } \\
\hline Death during VA- ECMO & 0 & $49(47)$ \\
\hline Successful weaning & 0 & $54(51)$ \\
\hline VA-ECMO to heart transplantation & 0 & $1(1.0)$ \\
\hline VA-ECMO to LVAD & 0 & $1(1.0)$ \\
\hline 90-d mortality & 0 & $60(57)$ \\
\hline Single non-CABG $(\mathrm{n}=30)$ & 0 & $14(47)$ \\
\hline Isolated CABG $(\mathrm{n}=21)$ & 0 & $18(86)$ \\
\hline 2 procedures* $(\mathrm{n}=33)$ & 0 & $17(52)$ \\
\hline 3 procedures* $(\mathrm{n}=21)$ & 0 & $11(52)$ \\
\hline In-hospital mortality & 0 & $59(56)$ \\
\hline Single non-CABG $(\mathrm{n}=30)$ & 0 & $13(43)$ \\
\hline Isolated CABG $(\mathrm{n}=21)$ & 0 & $18(86)$ \\
\hline 2 procedures* $(n=33)$ & 0 & $17(52)$ \\
\hline 3 procedures* $(\mathrm{n}=21)$ & 0 & $11(52)$ \\
\hline Discharge to home & 0 & $46(44)$ \\
\hline Single non-CABG $(\mathrm{n}=30)$ & 0 & $17(57)$ \\
\hline Isolated CABG $(\mathrm{n}=21)$ & 0 & $3(14)$ \\
\hline 2 procedures* $(\mathrm{n}=33)$ & 0 & $16(49)$ \\
\hline 3 procedures* $(n=21)$ & 0 & $10(48)$ \\
\hline $\begin{array}{l}\text { Days from VA-ECMO initiation to } \\
\text { discharge home }\end{array}$ & 0 & $64(41-105 ; 13-212)$ \\
\hline CPC score at discharge to home & 0 & $46(44)$ \\
\hline CPC $1-2$ & 0 & $46(100)$ \\
\hline СРC 3-4 & 0 & $0(0)$ \\
\hline Main cause of death during VA-ECMO & 0 & $49(47)$ \\
\hline Multiple organ failure & 0 & $24(23)$ \\
\hline Neurologic $\dagger$ & 0 & $9(8,6)$ \\
\hline Cardiac $\ddagger$ & 0 & $7(6.7)$ \\
\hline Bleeding $\S$ & 0 & $7(6.7)$ \\
\hline Miscellaneous $\|$ & 0 & $2(1.9)$ \\
\hline Main cause of death within $90 \mathrm{~d}$ & 0 & $60(57)$ \\
\hline Multiple organ failure & 0 & $29(28)$ \\
\hline Neurologic $\dagger$ & 0 & $12(11)$ \\
\hline Cardiac $\ddagger$ & 0 & $8(7.6)$ \\
\hline Bleeding $\S$ & 0 & $7(6.7)$ \\
\hline Miscellaneous $\|$, & 0 & $4(3.8)$ \\
\hline
\end{tabular}

Categoric and continuous variables are presented as $\mathrm{n}(\%)$ and median (IQR); range), respectively. $M D$, Missing data; $V A-E C M O$, venoarterial extracorporeal membrane oxygenation; $C A B G$, coronary artery bypass grafting; $L V A D$, left ventricular assist device; $C P C$, cerebral performance category. *Number of surgical interventions on the heart (euroSCORE II classification). †Stroke, fatal anoxia, brain death. ‡Sudden cardiac arrest, arrhythmia, myocardial infarction, heart failure. $\S$ Lung, gastrointestinal, and retroperitoneal bleeding. ||Iatrogenic air entry into the ECMO circuit $(\mathrm{n}=1)$, aortic dissection at cannulation $(\mathrm{n}=1)$. $\uparrow$ Massive pulmonary embolus $(\mathrm{n}=1)$, pulmonary embolus, and ischemic colitis $(\mathrm{n}=1)$. cannulation. Figure 1, A, depicts the cumulative KaplanMeier survival curves until 90 days after initiation of VAECMO related to arterial lactate intervals, indicating that an arterial lactate level $10 \mathrm{mmol} / \mathrm{L}$ or greater $(90.1 \mathrm{mg} / \mathrm{dL})$ had severely worse outcome $(P<.001)$. All patients with an arterial lactate level $15 \mathrm{mmol} / \mathrm{L}$ or greater $(135 \mathrm{mg} / \mathrm{dL})$ died within 20 days after VA-ECMO initiation. There was a significant difference in the cumulative 90-day survival between patients with and without IHD, $23 \%$ and $69 \%$, respectively $(P<.001)$ (Figure $1, B)$.

Of the 4 euroSCORE II cardiac surgical subgroups, isolated $\mathrm{CABG}$, even if not being an independent risk factor of 90-day mortality, had the worst prognosis with a sharp decrease in survival during the first 15 days, after which survival leveled out to $14 \%$ at 90 days after VA-ECMO initiation $(P<.001)$. In contrast, the other 3 cardiac surgical subgroups, single non-CABG and 2 and 3 concomitant surgical procedures had a 90 -day survival of approximately $50 \%$.

\section{DISCUSSION}

The main finding of this study was the identification of 2 independent pre-VA-ECMO risk factors for 90-day mortality in patients with RPCS, arterial lactate level, and IHD (Video 1). Furthermore, the 90-day and in-hospital mortality rates were $57 \%$ and $56 \%$, respectively, the latter being one of the lowest rates reported in unselected patients with RPCS.

Previous outcome studies have not focused specifically on pre-VA-ECMO risk factors for outcome, but rather on a combination of preoperative, surgical, and on-VAECMO (ie, during support) factors. However, to include on-VA-ECMO factors (ie, after cannulation) will obviously be problematic when the aim is to predict outcome at initiation of VA-ECMO (ie, just before cannulation). Furthermore, to focus merely on preoperative and intraoperative factors may be suitable only in patients who cannot be weaned from $\mathrm{CPB}$, that is, bridged directly from $\mathrm{CPB}$ to VA-ECMO, because $11 \%$ to $65 \%$ of patients ${ }^{11,13,14,16,17,24}$ were weaned from CPB and transferred to the intensive care unit before VA-ECMO was initiated because of hemodynamic deterioration after a varying number of hours or days. . $^{1,13,14,16,17,23}$

In the largest single-center study involving 517 patients with RPCS by Rastan and colleagues, ${ }^{13}$ only $40 \%$ were bridged directly from CPB to VA-ECMO. Numerous preoperative, surgical, and on-VA-ECMO factors were analyzed, whereby several independent risk factors for in-hospital mortality were identified. However, factors between weaning from CPB and start of VA-ECMO in the patients weaned from CPB were not included in their analysis, thereby blinding identification of specifically pre-VA-ECMO risk factors 
in the majority $(60 \%)$ of patients. Likewise, the second largest single-center study by Papadopoulos and colleagues, ${ }^{25}$ including 360 patients with PCS, identified 7 independent risk factors for in-hospital mortality, although type of cannulation, an on-VA-ECMO risk factor, was included in their analysis. Consequently, in addition to preoperative and surgical factors, we retrospectively identified several complementary variables after surgery until the start of VA-ECMO. To our knowledge, our study is the first to specifically focus on identifying pre-VA-ECMO risk factors for 90-day mortality in an unselected patient population with RPCS.

We identified 2 significant independent risk factors associated with 90-day mortality. First, lactate had an OR of 1.22 per $\mathrm{mmol} / \mathrm{L}$, implying progressively worse outcomes with increasing lactate levels. High lactate levels at the end of cardiac surgery due to an imbalance between oxygen demand and supply ultimately leading to tissue hypoxia and organ failure have been described as an independent risk factor of negative outcome after cardiac surgery. ${ }^{26-28}$ The physiologic background is that lactate is a metabolic end product of anaerobic glycolysis, which is produced by the reduction of pyruvate and primarily removed by the liver. Lactate is considered to be a marker of tissue perfusion, which is affected by both macro- and microcirculation, whereas routine hemodynamic parameters have been suggested to be unreliable. On the basis of our daily practice, we divided the study population into 4 chosen subgroups of lactate with arbitrary cutoff levels of less than $5 \mathrm{mmol} / \mathrm{L}, 5$ to $9.9 \mathrm{mmol} / \mathrm{L}, 10$ to $14.9 \mathrm{mmol} / \mathrm{L}$, and $15 \mathrm{mmol} / \mathrm{L}$ or greater (Table 1 ) to facilitate clinical interpretation of lactate as a strong and significant risk factor. In addition, the cutoff level of 10 or greater was chosen (Figure 1) because it corresponded to a specificity of $91 \%$ (receiver operating characteristic survival of $9 \%$ ), implying that a lactate level of 10 identified more than $90 \%$ of the patients who died in our study population. A cutoff level of $15 \mathrm{mmol} / \mathrm{L}$ would have identified $100 \%$ of nonsurvivors and at the same time raised the question if ECMO out of ethical reasons should be offered to patients with an approximately $100 \%$ expected mortality. Moreover, our finding of arterial lactate as an independent pre-VA-ECMO risk factor of mortality after cardiac surgery is compatible with the findings of Park and colleagues, ${ }^{14,29}$ who in 2 studies including 115 and 93 patients, respectively, identified blood lactate before initiation of extracorporeal life support (ie, VA-ECMO) as an independent risk factor of in-hospital mortality (OR per unit lactate, 1.19 and 1.13, respectively). Likewise, Papadopoulos and colleagues ${ }^{25}$ found that a pre-VA-ECMO serum lactate level of greater than $120 \mathrm{mg} / \mathrm{dL}(>13.3 \mathrm{mmol} / \mathrm{L})$ adversely affected inhospital survival (OR, 2.6), as did Rastan and colleagues, ${ }^{13}$ who found that a lactate level greater than $4 \mathrm{mmol} / \mathrm{L}$ in the operating room and greater than $10 \mathrm{mmol} / \mathrm{L}$ immediately after VA-ECMO initiation were significant risk factors of in-hospital mortality (OR, 2.21 and 2.65, respectively). Furthermore, an important feature that strengthens the impact of arterial lactate as a risk factor was that we were able to identify specific intervals of arterial lactate indicating progressively worse outcomes as illustrated in Figure 1, A, and Table 1, which to our knowledge is the first time to be reported in RPCS in a pre-VA-ECMO setting.

The second independent risk factor, IHD, was the only organ-specific risk factor of mortality, which is supported by previous studies indicating that patients with IHD have worse expected outcome compared with patients without IHD $^{11,30}$ (Figure 1, $B$ ). Obviously, all patients who received planned CABG had IHD. These factors were highly correlated in the multicollinearity analysis. However, not all patients with IHD received grafts unless there was significant and graftable stenosis, whereby IHD had a higher prevalence than CABG. Thus, we kept IHD and excluded $\mathrm{CABG}$ from the model. In addition to the significant correlation between IHD and CABG, AMI correlated significantly with IHD and was removed from the model, besides being included in the definition of IHD. Our analysis further demonstrated that none of the 4 euroSCORE II cardiac surgical subgroups, cardioplegic route, or time
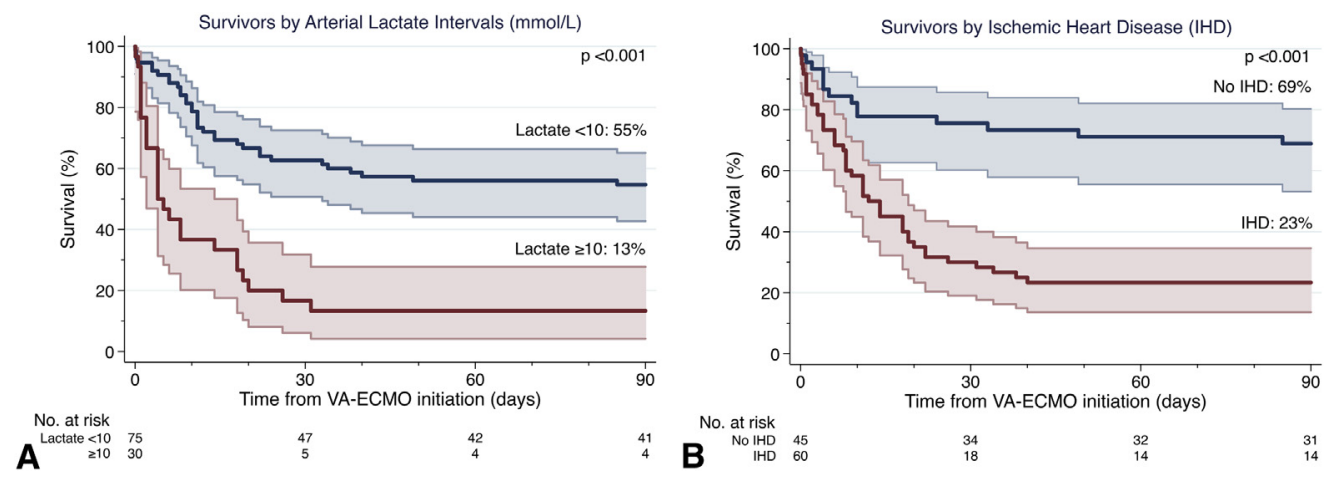

FIGURE 1. Kaplan-Meier survival curves until 90 days after initiation of VA-ECMO support related to (A) arterial lactate intervals and (B) presence of IHD, with $95 \%$ confidence intervals, at initiation of VA-ECMO in 105 patients with RPCS. VA-ECMO, Venoarterial extracorporeal membrane oxygenation. 


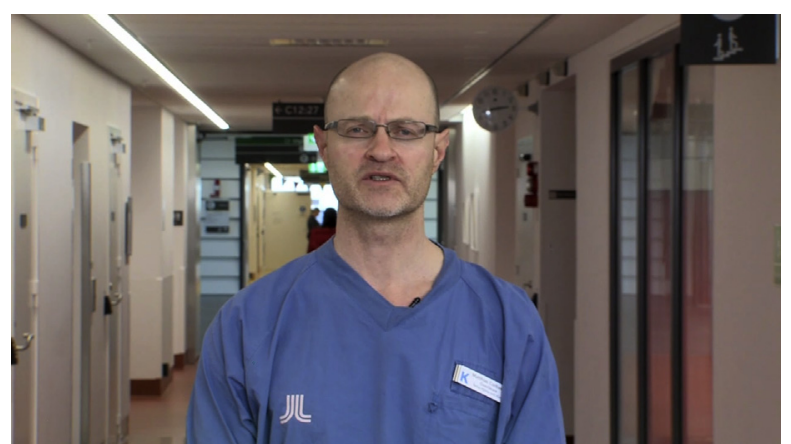

VIDEO 1. A video of Matthias Corbascio, $\mathrm{MD}, \mathrm{PhD}$, one of the authors, explaining the importance and relevance of the article for the readers of the Journal. Video available at: https://www.jtcvs.org/article/S0022-5223(18) 31487-9/fulltext.

on CPB independently predicted 90-day mortality (Table E1), although isolated CABG had a significantly worse outcome at 90 days compared with the other surgical subgroups (Table 1). Thus, the extent of tissue hypoperfusion in RPCS, as indicated by lactate levels and the presence of IHD, appeared to be more important than other variables that otherwise affect postoperative outcomes, such as patient characteristics, comorbidities, type of surgical procedure, cardioplegic route, aortic crossclamp, and CPB time. In contrast to several other studies, ${ }^{11-14,16,17,21,24,25,31}$ age did not reach significance in our multivariable analysis. This could be a type II error, but more likely suggests that in previous less-adjusted analyses age was important, whereas in our analysis, age was neutralized by the many other covariates in the model and risk more directly reflected by severity of hypoperfusion and thus lactate increase.

Our primary end point mortality within 90 days after VA-ECMO initiation was chosen over 30-day mortality because $6.7 \%$ of the patients (7/105) had VA-ECMO support 30 days or more (up to 55 days). Also, the KaplanMeier survival curves flattened out before reaching 90 days, indicating that an extension beyond 90 days would not add further clarity to midterm outcome. Given the nonproportional hazards with early high risk, we preferred logistic regression for categoric vital status at 90 days rather than Cox regression for time-dependent outcomes analyses. Moreover, we preferred the outcome variable mortality at 90 days to the alternative alive at hospital discharge because the former includes a specific time span and not a subjectively decided point of time for discharge from the hospital.

Our in-hospital mortality rate was $56 \%$, which to our knowledge is one of the lowest single-center mortality rates reported in an unselected population with RPCS supported with VA-ECMO. In comparison, previous studies have reported in-hospital mortality rates of $53.4 \%$ to $76.3 \%{ }^{11,13,19,25}$ Our incidence of postcardiotomy VAECMO was $1.3 \%$, which is in the midrange of other reported studies $(0.6 \%-2.9 \%)$ and almost equal to the large studies by Rastan and colleagues, ${ }^{13} 1.3 \%$, and Doll and colleagues, ${ }^{11} 1.2 \%$. Nonetheless, outcomes are overall poor, which highlights the need to rigorously identify risk factors and develop tools to optimize selection of appropriate patients with RPCS who profit from VA-ECMO.

We successfully weaned $51 \%$ of our patients from VAECMO compared with between $31 \%$ and $63.5 \%$ in previous studies. ${ }^{11,13,21,25}$ However, comparisons of studies are challenging because of nonreporting of data and lack of a clear definition over what is to be regarded as successful in terms of survival time after weaning. ${ }^{13,24}$ Besides comparing patient characteristics, weaning, and bridging rates, the reported rate of successful weaning should also be related to the number of patients discharged alive without having been bridged to heart transplantation or VAD, regardless of having survived weaning with an arbitrary defined number of hours or days.

\section{Study Limitations}

This retrospective observational study with heterogeneous surgical patients did not allow for randomization or include a matched control cohort. However, its heterogeneity reflects the clinical reality in patients with RPCS and provides for external validity (generalizability) of our findings.

\section{CONCLUSIONS}

In patients with RPCS, arterial lactate level and presence of IHD were independent pre-VA-ECMO risk factors of 90day mortality. These variables are easily available and may facilitate early prediction of outcome and improve use of VA-ECMO in these critically ill patients. Our data suggest that VA-ECMO should be considered before profound hyperlactatemia occurs, especially in patients with IHD. In contrast, age, type of cardiac surgery, euroSCORE II, and $\mathrm{CPB}$ duration did not predict outcome independently.

\section{Conflict of Interest Statement}

Authors have nothing to disclose with regard to commercial support.

The authors thank Anders Franco-Cereceda, Professor of Cardiothoracic Surgery and Head of Department of Molecular Medicine and Surgery, Karolinska Institutet, Karolinska University Hospital, for supporting this project.

\section{References}

1. Pennington DG, Swartz M, Codd JE, Merjavy JP, Kaiser GC. Intraaortic balloon pumping in cardiac surgical patients: a nine-year experience. Ann Thorac Surg. 1983;36:125-31.

2. Sylvin EA, Stern DR, Goldstein DJ. Mechanical support for postcardiotomy cardiogenic shock: has progress been made? J Card Surg. 2010;25:442-54.

3. Reyentovich A, Barghash MH, Hochman JS. Management of refractory cardiogenic shock. Nat Rev Cardiol. 2016;13:481-92.

4. Goldstein DJ, Oz MC. Mechanical support for postcardiotomy cardiogenic shock. Semin Thorac Cardiovasc Surg. 2000;12:220-8. 
5. Westaby S, Balacumaraswami L, Sayeed R. Maximizing survival potential in very high risk cardiac surgery. Heart Fail Clin. 2007;3:159-80.

6. Fukuhara S, Takeda K, Garan AR, Kurlansky P, Hastie J, Naka Y, et al. Contemporary mechanical circulatory support therapy for postcardiotomy shock. Gen Thorac Cardiovasc Surg. 2016;64:183-91.

7. Golding LA. Postcardiotomy mechanical support. Semin Thorac Cardiovasc Surg. 1991;3:29-32.

8. Hausmann H, Potapov EV, Koster A, Krabatsch T, Stein J, Yeter R, et al. Prognosis after the implantation of an intra-aortic balloon pump in cardiac surgery calculated with a new score. Circulation. 2002;106:I203-6.

9. Abrams D, Combes A, Brodie D. Extracorporeal membrane oxygenation in cardiopulmonary disease in adults. J Am Coll Cardiol. 2014;63:2769-78.

10. Westaby S, Anastasiadis K, Wieselthaler GM. Cardiogenic shock in ACS. Part 2: Role of mechanical circulatory support. Nat Rev Cardiol. 2012;9:195-208.

11. Doll N, Kiaii B, Borger M, Bucerius J, Krämer K, Schmitt DV, et al. Fiveyear results of 219 consecutive patients treated with extracorporeal membrane oxygenation for refractory postoperative cardiogenic shock. Ann Thorac Surg. 2004;77:151-7; discussion 157.

12. Elsharkawy HA, Li L, Esa WA, Sessler DI, Bashour CA. Outcome in patients who require venoarterial extracorporeal membrane oxygenation support after cardiac surgery. J Cardiothorac Vasc Anesth. 2010;24:946-51.

13. Rastan AJ, Dege A, Mohr M, Doll N, Falk V, Walther T, et al. Early and late outcomes of 517 consecutive adult patients treated with extracorporeal membrane oxygenation for refractory postcardiotomy cardiogenic shock. J Thorac Cardiovasc Surg. 2010;139:302-11.e301.

14. Park SJ, Kim JB, Jung SH, Choo SJ, Chung CH, Lee JW. Outcomes of extracorporeal life support for low cardiac output syndrome after major cardiac surgery. $J$ Thorac Cardiovasc Surg. 2014;147:283-9.

15. Hsu PS, Chen JL, Hong GJ, Tsai Y, Lin CY, Lee CY, et al. Extracorporeal membrane oxygenation for refractory cardiogenic shock after cardiac surgery: predictors of early mortality and outcome from 51 adult patients. Eur J Cardiothorac Surg. 2010;37:328-33.

16. Guihaire J, Dang Van S, Rouze S, Rosier S, Roisne A, Langanay T, et al. Clinical outcomes in patients after extracorporeal membrane oxygenation support for post-cardiotomy cardiogenic shock: a single-centre experience of 92 cases. Interact Cardiovasc Thorac Surg. 2017;25:363-9.

17. Li CL, Wang H, Jia M, Ma N, Meng X, Hou XT. The early dynamic behavior of lactate is linked to mortality in postcardiotomy patients with extracorporeal membrane oxygenation support: a retrospective observational study. J Thorac Cardiovasc Surg. 2015;149:1445-50.

18. Chen SW, Tsai FC, Lin YS, Chang CH, Chen DY, Chou AH, et al. Long-term outcomes of extracorporeal membrane oxygenation support for postcardiotomy shock. J Thorac Cardiovasc Surg. 2017;154:469-77.e462.

19. Loforte A, Marinelli G, Musumeci F, Folesani G, Pilato E, Martin Suarez S, et al Extracorporeal membrane oxygenation support in refractory cardiogenic shock: treatment strategies and analysis of risk factors. Artif Organs. 2014;38:E129-41.
20. Whitman GJ. Extracorporeal membrane oxygenation for the treatment of postcardiotomy shock. J Thorac Cardiovasc Surg. 2017;153:95-101.

21. Fiser SM, Tribble CG, Kaza AK, Long SM, Zacour RK, Kern JA, et al. When to discontinue extracorporeal membrane oxygenation for postcardiotomy support. Ann Thorac Surg. 2001;71:210-4

22. Squiers JJ, Lima B, DiMaio JM. Contemporary extracorporeal membrane oxygenation therapy in adults: fundamental principles and systematic review of the evidence. J Thorac Cardiovasc Surg. 2016;152:20-32.

23. Bakhtiary F, Keller H, Dogan S, Dzemali O, Oezaslan F, Meininger D, et al. Venoarterial extracorporeal membrane oxygenation for treatment of cardiogenic shock: clinical experiences in 45 adult patients. J Thorac Cardiovasc Surg. 2008; 135:382-8.

24. Slottosch I, Liakopoulos O, Kuhn E, Deppe AC, Scherner M, Madershahian N, et al. Outcomes after peripheral extracorporeal membrane oxygenation therapy for postcardiotomy cardiogenic shock: a single-center experience. J Surg Res. 2013; 181:e47-55.

25. Papadopoulos N, Marinos S, El-Sayed Ahmad A, Keller H, Meybohm P, Zacharowski K, et al. Risk factors associated with adverse outcome following extracorporeal life support: analysis from 360 consecutive patients. Perfusion. 2015;30:284-90.

26. Hajjar LA, Almeida JP, Fukushima JT, Rhodes A, Vincent JL, Osawa EA, et al. High lactate levels are predictors of major complications after cardiac surgery. $J$ Thorac Cardiovasc Surg. 2013;146:455-60.

27. Lopez-Delgado JC, Esteve F, Javierre C, Torrado H, Rodriguez-Castro D, Carrio ML, et al. Evaluation of serial arterial lactate levels as a predictor of hospital and long-term mortality in patients after cardiac surgery. J Cardiothorac Vasc Anesth. 2015;29:1441-53.

28. Haanschoten MC, Kreeftenberg HG, Arthur Bouwman R, van Straten AH, Buhre WF, Soliman Hamad MA. Use of postoperative peak arterial lactate level to predict outcome after cardiac surgery. J Cardiothorac Vasc Anesth. 2017;31:45-53.

29. Park SJ, Kim SP, Kim JB, Jung SH, Choo SJ, Chung CH, et al. Blood lactate level during extracorporeal life support as a surrogate marker for survival. J Thorac Cardiovasc Surg. 2014;148:714-20.

30. Finegold JA, Asaria P, Francis DP. Mortality from ischaemic heart disease by country, region, and age: statistics from World Health Organisation and United Nations. Int J Cardiol. 2013;168:934-45.

31. Wu MY, Lin PJ, Lee MY, Tsai FC, Chu JJ, Chang YS, et al. Using extracorporeal life support to resuscitate adult postcardiotomy cardiogenic shock: treatment strategies and predictors of short-term and midterm survival. Resuscitation. 2010;81:1111-6.

Key Words: extracorporeal life support, extracorporeal membrane oxygenation, ischemic heart disease, lactate, postcardiotomy cardiogenic shock 


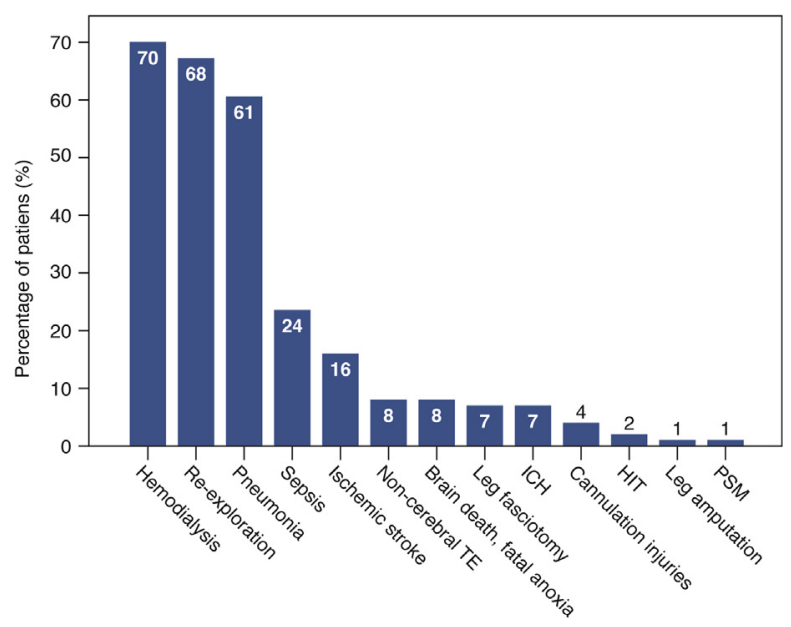

FIGURE E1. Main complications after initiation of venoarterial extracorporeal membrane oxygenation support in 105 patients with refractory postcardiotomy cardiogenic shock. TE, Thromboembolism; $I C H$, intracranial hemorrhage; HIT, heparin induced thrombocytopenia; PSM, poststernotomy mediastinitis. 
TABLE E1. Factors associated with mortality within 90 days after venoarterial extracorporeal membrane oxygenation initiation

\begin{tabular}{|c|c|c|c|c|c|}
\hline \multirow[b]{2}{*}{ Variables } & \multirow{2}{*}{$\begin{array}{l}\text { MD } \\
(\%)\end{array}$} & \multicolumn{2}{|c|}{ Univariable logistic regression } & \multicolumn{2}{|c|}{ Multivariable logistic regression } \\
\hline & & OR $(95 \%$ CI $)$ & $P$ value & OR $(95 \%$ CI $)$ & $P$ value \\
\hline Male sex & 0 & $1.32(0.53-3.24)$ & .552 & - & - \\
\hline Age $(y)$ & 0 & $1.04(1.01-1.07)$ & .017 & $1.04(0.99-1.09)$ & .058 \\
\hline Age $\geq 65$ y vs. $<65$ y & 0 & $2.30(1.01-5.23)$ & .046 & - & - \\
\hline Weight (kg) & 0 & $1.00(0.98-1.02)$ & .970 & - & - \\
\hline BMI $\left(\mathrm{kg} / \mathrm{m}^{2}\right)$ & 0 & $0.99(0.92-1.07)$ & .800 & - & - \\
\hline euroSCORE II & 0 & $1.03(0.99-1.05)$ & .071 & - & - \\
\hline euroSCORE II critical preoperative state & 0 & $1.05(0.47-2.35)$ & .907 & - & - \\
\hline \multicolumn{6}{|l|}{ euroSCORE II type of cardiac surgery } \\
\hline Single non-CABG & 0 & $0.55(0.24-1.30)$ & .173 & - & - \\
\hline Isolated CABG & 0 & $6.00(1.64-21.9)$ & .007 & - & - \\
\hline 2 procedures* & 0 & $0.72(0.31-1.64)$ & .431 & - & - \\
\hline 3 procedures* & 0 & $0.62(0.30-2.05)$ & .622 & - & - \\
\hline \multicolumn{6}{|l|}{ euroSCORE II urgency of surgery } \\
\hline Elective & 0 & $0.50(0.23-1.09)$ & .081 & - & - \\
\hline Urgent & 0 & $1.04(0.38-2.84)$ & .942 & - & - \\
\hline Emergency & 0 & $1.71(0.69-4.28)$ & .249 & - & - \\
\hline Salvage & 0 & $2.15(0.54-8.63)$ & .279 & - & - \\
\hline \multicolumn{6}{|l|}{ Type of cardioplegia } \\
\hline No cardioplegia & 0 & Reference & - & - & - \\
\hline Antegrade cardioplegia & 0 & $1.53(0.46-5.14)$ & .492 & - & - \\
\hline Antegrade + retrograde cardioplegia & 0 & $1.26(0.38-4.23)$ & .705 & - & - \\
\hline Retrograde cardioplegia & 0 & $1.50(0.19-11.93)$ & .702 & - & - \\
\hline Cross clamp time (min) & 2.9 & $0.997(0.99-1.00)$ & .206 & - & - \\
\hline CPB time (min) & 2.9 & $1.00(0.99-1.00)$ & .738 & - & - \\
\hline From CPB direct to VA-ECMO in the operating room & 0 & $1.14(0.53-2.48)$ & .735 & - & - \\
\hline Acute myocardial infarction & 0 & $4.97(1.71-14.4)$ & .003 & - & - \\
\hline Ischemic heart disease & 0 & $7.28(3.05-17.4)$ & $<.001$ & $7.87(2.55-24.3)$ & $<.001$ \\
\hline Smoking & 0 & $1.64(0.75-3.56)$ & .216 & - & - \\
\hline Hypertension & 0 & $1.334(0.62-2.90)$ & .464 & - & - \\
\hline Valvular heart disease & 0 & $0.56(0.24-1.32)$ & .184 & - & - \\
\hline Congestive heart failure & 0 & $0.95(0.41-2.20)$ & .903 & - & - \\
\hline Diabetes mellitus & 0 & $2.00(0.65-6.16)$ & .227 & - & - \\
\hline Atrial fibrillation & 0 & $1.58(0.63-3.97)$ & .330 & - & - \\
\hline Dyslipidemia & 0 & $1.53(0.67-3.50)$ & .314 & - & - \\
\hline Previous* myocardial infarction & 0 & $1.98(0.69-5.64)$ & .202 & - & - \\
\hline Previous $\dagger$ PCI & 0 & $2.15(0.54-8.63)$ & .279 & - & - \\
\hline Previous $\dagger$ cardiac surgery & 0 & $1.50(0.61-3.67)$ & .374 & - & - \\
\hline Previous $\dagger$ CABG & 0 & $4.30(0.89-20.7)$ & .069 & - & - \\
\hline Renal failure & 0 & $2.05(0.60-7.02)$ & .253 & - & - \\
\hline Hypertrophic cardiomyopathy & 0 & $2.05(0.60-7.02)$ & .253 & - & - \\
\hline Endocarditis & 0 & $0.42(0.10-1.86)$ & .254 & - & - \\
\hline Primary graft failure after HTX & 0 & $0.54(0.12-2.54)$ & .435 & - & - \\
\hline $\operatorname{LVEF}(\%) \ddagger$ & 0 & $0.96(0.94-0.98)$ & $<.001$ & $0.98(0.95-1.01)$ & .112 \\
\hline$<20$ vs. $\geq 20(\%)$ & 0 & $4.75(2.04-11.1)$ & $<.001$ & - & - \\
\hline
\end{tabular}


TABLE E1. Continued

\begin{tabular}{|c|c|c|c|c|c|}
\hline \multirow[b]{2}{*}{ Variables } & \multirow{2}{*}{$\begin{array}{l}\text { MD } \\
(\%)\end{array}$} & \multicolumn{2}{|c|}{ Univariable logistic regression } & \multicolumn{2}{|c|}{ Multivariable logistic regression } \\
\hline & & OR $(95 \%$ CI $)$ & $P$ value & OR $(95 \%$ CI $)$ & $P$ value \\
\hline MAP $(\mathrm{mm} \mathrm{Hg}) \ddagger$ & 0 & $0.96(0.94-0.99)$ & .007 & $0.98(0.95-1.04)$ & .243 \\
\hline$<50$ vs. $\geq 50(\mathrm{~mm} \mathrm{Hg})$ & 0 & $3.78(1.62-8.83)$ & .002 & - & - \\
\hline \multicolumn{6}{|l|}{ Laboratory values } \\
\hline Arterial $\mathrm{pH}_{\ddagger}^{\dagger}$ & 0 & $0.03(0.00-0.53)$ & .017 & - & - \\
\hline Arterial lactate $(\mathrm{mmol} / \mathrm{L}) \ddagger$ & 0 & $1.21(1.10-1.33)$ & $<.001$ & $1.22(1.07-1.40)$ & .004 \\
\hline Hemoglobin $(\mathrm{g} / \mathrm{L}) \ddagger$ & 0 & $0.998(0.98-1.02)$ & .851 & - & - \\
\hline WBC $\left(10^{9} / \mathrm{L}\right)$ & 0 & $0.97(0.93-1.02)$ & .269 & - & - \\
\hline Platelets $\left(10^{9} / \mathrm{L}\right)$ & 0 & $0.999(0.99-1.00)$ & .576 & - & - \\
\hline Creatinine $(\mu \mathrm{mol} / \mathrm{L})$ & 0 & $1.00(0.99-1.01)$ & .686 & - & - \\
\hline $\operatorname{GFR} \operatorname{MDRD}\left(\mathrm{mL} / \mathrm{min} / 1.73 \mathrm{~m}^{2}\right)$ & 0 & $0.99(0.97-1.00)$ & .051 & - & - \\
\hline $\operatorname{ALT}(\mu \mathrm{kat} / \mathrm{L})$ & 5.7 & $1.00(0.97-1.04)$ & .923 & - & - \\
\hline Pre-VA-ECMO interventions & 0 & & & & \\
\hline Acute PCI & 0 & $1.96(0.36-10.6)$ & .436 & - & - \\
\hline Hemodialysis & 0 & $1.07(0.42-2.68)$ & .893 & - & - \\
\hline CPR & 0 & $1.27(0.54-3.00)$ & .579 & - & - \\
\hline No. of inotropes and vasopressors $\S$ & 0 & $1.42(0.99-2.04)$ & .055 & - & - \\
\hline Retrieval from external hospital & 0 & $1.68(0.65-4.37)$ & .286 & - & - \\
\hline VA-ECMO insertion period, $2011-2015$ vs. $2011-2015$ & 0 & $0.45(0.22-1.07)$ & .073 & - & - \\
\hline
\end{tabular}

$M D$, Missing data; $O R$, odds ratio; $C I$, confidence interval; $B M I$, body mass index; euroSCORE, European System for Cardiac Operative Risk Evaluation; $C A B G$, coronary artery bypass grafting; $C P B$, cardiopulmonary bypass; VA-ECMO, venoarterial extracorporeal membrane oxygenation; $P C I$, percutaneous coronary intervention; $H T X$, heart transplantation; $L V E F$, left ventricular ejection fraction; $M A P$, mean arterial pressure; WBC, white blood cell counts; GFR MDRD, glomerular filtration rate modification of diet in renal disease; $A L T$, alanine aminotransferase; $C P R$, cardiopulmonary resuscitation. *Number of surgical interventions on the heart (euroSCORE II classification). $\dagger$ Before current medical event or admission. $\ddagger$ Just before cannulation. §Epinephrine, norepinephrine, dobutamine, dopamine, vasopressin, milrinone, and levosimendan. 